\title{
EL SISTEMA ELECTORAL GALLEGO: REFORMAR, O NO REFORMAR, ESA ES LA CUESTIÓN
}

CARLOS FERNÁNDEZ ESQUER

JOSÉ RAMA CAAMAÑO 
SUMARIO

I. INTRODUCCIÓN. II. EL SISTEMA ELECTORAL GALLEGO: 1. EL CONTEXTO ELECTORAL AUTONÓMICO 2. EL ORIGEN DEL SISTEMA ELECTORAL GALLEGO. 3. EL SISTEMA ELECTORAL GALLEGO EN LA ACTUALIDAD. III. CONSECUENCIAS POLÍTICAS DEL SISTEMA ELECTORAL. IV. REFORMAS Y PROPUESTAS DE REFORMA DEL SISTEMA ELECTORAL GALLEGO: 1. LA POLÉMICA REFORMA DE 1992. 2. PROPUESTAS DE REFORMA EN 2012 Y 2014. V. UNA HUMILDE PROPUESTA DE REFORMA ELECTORAL. VI. CONCLUSIONES. 


\title{
EL SISTEMA ELECTORAL GALLEGO: REFORMAR, O NO REFORMAR, ESA ES LA CUESTIÓN
}

\author{
CARLOS FERNÁNDEZ ESQUER \\ Investigador predoctoral \\ (Universidad Autónoma de Madrid) \\ JOSÉ RAMA CAAMAÑO ${ }^{1}$ \\ Investigador predoctoral \\ (Universidad Autónoma de Madrid)
}

\section{INTRODUCCIÓN}

Se han celebrado un total de diez elecciones autonómicas en Galicia desde los primeros comicios regionales de 1981. Por aquel entonces ya se intuía que la competición política se disputaría entre fuerzas progresistas, conservadoras y nacionalistas. A pesar de que la Unión de Centro Democrático (UCD) era aún el partido de gobierno a nivel nacional, fue Alianza Popular (AP) — que hasta el momento había cosechado unos modestos resultados en las elecciones generales - el partido vencedor de las primeras elecciones gallegas. Desde entonces, AP — posteriormente Partido Popular (PP) — ha sido el partido hegemónico en Galicia, como demuestra su gobierno continuado en esta Comunidad Autónoma, sólo interrumpido en dos momentos concretos: el período 1987-1989 tras la moción de censura que derrocó a Gerardo Fernández Albor (AP) y puso en su lugar al socialista Fernando González Laxe; y el histórico bipartito gallego de la VII Legislatura (2005-2009), en el que el Partido de los Socialistas de Galicia-PSOE (PSOE) y el Bloque Nacionalista Galego (BNG) llegaron a un acuerdo para gobernar conjuntamente bajo la presidencia de Emilio Pérez Touriño.

1 Los autores aparecen en orden alfabético y comparten a partes iguales los contenidos de este trabajo. José Rama Caamaño es Investigador predoctoral en la Facultad de Derecho de la Universidad Autónoma de Madrid. Calle Kelsen, 1, 28049 Madrid. Email: jose.rama@uam.es. Carlos Fernández Esquer también es Investigador predoctoral en la Facultad de Derecho de la Universidad Autónoma de Madrid. Email: carlos.fernandeze@uam.es. 
A lo largo de este tiempo, el sistema de partidos gallego ha conocido la entrada, consolidación, escisión, confluencia y desaparición de distintas formaciones políticas. Entre 1981 y 2016 hasta ocho candidaturas han conseguido representación en el Parlamento de Galicia ${ }^{2}$. Sin embargo, el sistema electoral gallego ha sido criticado en ocasiones por dificultar la entrada en la Casona del Hórreo a determinados partidos, como consecuencia de su importante barrera de acceso y de su sesgo mayoritario. Además, la sobrerrepresentación de las zonas rurales y la consecuente infrarrepresentación de las áreas urbanas, habría generado desigualdades en el valor de los sufragios entre los electores de las cuatro provincias.

Curiosamente, Galicia es una de las pocas comunidades autónomas que ha modificado levemente su sistema electoral: en el año 1992, se elevó la barrera electoral del 3 al 5 por ciento. Con posterioridad también se han presentado varias propuestas de reforma en las distintas legislaturas, aunque finalmente ninguna de ellas ha culminado. No obstante, ni la reforma de 1992 ni las propuestas de reforma más relevantes han buscado procurar una mayor proporcionalidad o reducir las desigualdades en el valor del voto; antes al contrario, han pretendido endurecer las barreras de entrada a las pequeñas organizaciones políticas. En cualquier caso, resulta interesante, no sólo conocer los detalles concretos de las propuestas de reforma electoral, sino realizar simulaciones sobre qué habría pasado en términos de representación parlamentaria si se hubiesen aplicado otras reglas electorales en los recientes comicios autonómicos que tuvieron lugar el 25 de septiembre de 2016.

Con tal objetivo, el presente trabajo se estructura de la siguiente forma. Tras esta breve introducción, describiremos los principales elementos del sistema electoral gallego que, a su vez, comparamos con el resto de sistemas electorales que se aplican en otras comunidades autónomas. A continuación, trataremos de explicar las razones que ayudan a entender la configuración inicial del sistema electoral gallego. El siguiente apartado describe el impacto del sistema electoral en distintas dimensiones: la fragmentación partidista, la desproporcionalidad de los resultados, las bonificaciones y penalizaciones proyectadas sobre los partidos y la desigualdad en el valor del voto. Una vez analizados los rendimientos del sistema, describiremos las reformas y propuestas de reforma formuladas por el partido de gobierno. Posteriormente, esbozaremos qué hubiese pasado en las últimas elecciones de 2016 si se hubiesen aplicado otras reglas electorales. Por último, estaremos en condiciones de cerrar el artículo con una propuesta de reforma electoral propia y unas breves conclusiones.

${ }^{2}$ Las ocho candidaturas que han obtenido representación son PP, PSOE, UCD, BNG, Coalición Galega (CG), Esquerda Galega (EG), En Marea y Partido Comunista de Galicia (PCG). Aunque algunos de los partidos y coaliciones que se muestran a continuación no siempre concurrieron a las elecciones conjuntamente, a los efectos de este trabajo y en aras de la simplificación, consideramos que son una misma candidatura: Alianza Popular (AP), Coalición Popular de Galicia (CP) y el Partido Popular (PP); Esquerda Galega (EG) y el Partido Socialista Galego (PSG); el Bloque Nacionalista-Partido Galego (BNPG) y el Bloque Nacionalista Galego (BNG); y Alternativa Galega de Esquerda (AGE) y En Marea. 


\section{EL SISTEMA ELECTORAL GALLEGO}

\section{El contexto electoral autonómico}

Durante la transición democrática, la generalización de las autonomías en todo el territorio español desembocó en la instauración de diecisiete Asambleas Legislativas autonómicas. Pese a que el artículo 152.1 de la Constitución Española (CE) solamente obligaba a ello a las comunidades que se habían constituido por la «vía rápida» del artículo $151 \mathrm{CE}$, las que siguieron la «vía lenta» también terminaron sumándose a la forma de gobierno parlamentaria. Los Acuerdos autonómicos de 1981, consensuados entre el PSOE y la UCD, dotaron a todas las comunidades, siguiendo el artículo 152.1 CE, de una «Asamblea Legislativa, elegida por sufragio universal, con arreglo a un sistema de representación proporcional que asegure, además, la representación de las diversas zonas del territorio» ${ }^{3}$.

De esta forma, las Comunidades disponían de un amplio espacio de libertad para configurar los elementos básicos de sus respectivos sistemas electorales: el tamaño de los parlamentos, la fórmula electoral para repartir los escaños, la delimitación territorial de las circunscripciones, la magnitud de los distritos, la barrera electoral, o el tipo de candidaturas ${ }^{4}$. Pese a ello, la innovación brilló por su ausencia ${ }^{5}$. Una buena parte de la normativa electoral autonómica se limita a recoger la regulación de la LOREG, cuando no se remite simplemente a sus artículos. Como ha señalado Juan Carlos Gavara, «el régimen electoral español se caracteriza por la permanencia y continuidad desde los inicios de la transición política, hasta el punto que los elementos básicos del sistema electoral no han sido modificados, en relación con las reglas generales que se han remitido de forma mimética a las leyes electorales autonómicas, es decir, se ha ido produciendo una homogeneidad de regulaciones y criterios desde un punto de vista práctico» ${ }^{6}$. Buena prueba de esta escasa creatividad de los legisladores

3 Cabe apuntar que se suscitó un interesante debate doctrinal acerca de si el sistema electoral de las Comunidades Autónomas no constituidas por la vía del artículo 151 CE también debían seguir necesariamente las directrices del artículo 152.1 CE, o si, por el contrario, disponían de plena libertad al respecto. Finalmente, y pese al tenor literal del referido artículo, el Tribunal Constitucional, en la STC 225/1998, de 25 de noviembre, acabó respaldando la tesis de quienes sostenían que las previsiones del artículo 152.1 CE se proyectaban sobre los Estatutos de Autonomía de todas las Comunidades Autónomas, con independencia de su respectiva vía de acceso a la autonomía. Jurisprudencia que se ha visto confirmada recientemente en las SSTC 19/2011, de 3 de marzo, 197/2014, de 4 de diciembre y $15 / 2015$, de 5 de febrero.

4 Para una visión general de los sistemas electorales autonómicos, resulta de especial interés la monografía de J. OLIVER ARAUJO, Los sistemas electorales autonómicos. Barcelona: Generalitat de Catalunya, Departament de Governació i Relacións Institucionals, 2011.

5 F, PALLARÉS, «Los sistemas electorales de las Comunidades Autónomas. Aspectos institucionales» en J. MONTABES (ed.), El sistema electoral a debate. Veinte años de rendimientos del sistema electoral español, Madrid: Centro de Investigaciones Sociológicas/Parlamento de Andalucía, 1998, pp. 221-246.

${ }^{6}$ J. C., GAVARA DE CARA, La homogeneidad de los regímenes electorales autonómicos. Madrid: Centro de Estudios Políticos y Constitucionales, 2007, p. 20. 
autonómicos en materia electoral es la utilización generalizada de la fórmula D`Hondt y de las listas cerradas y bloqueadas en todos los sistemas electorales autonómicos.

Con todo, es posible hacer algunas precisiones que matizan la consideración anterior. A pesar de que, efectivamente, existen elementos que se reiteran en todos los sistemas autonómicos, existe cierta innovación en otros. Aunque la regla general es la utilización de la provincia como circunscripción —al igual que ocurre en los sistemas electorales del Congreso y del Senado_- existen cuatro comunidades autónomas que se han inclinado por un tipo de circunscripción de base territorial distinta a la provincial. Por un lado, Canarias e Islas Baleares han optado por la utilización de la isla como circunscripción. Por su parte, el Principado de Asturias — y la Región de Murcia hasta hace poco tiempo - , han decidido fraccionar sus territorios en varios distritos electorales, rompiendo la tendencia asumida por el resto de comunidades peninsulares uniprovinciales, consistente en adoptar la provincia como circunscripción.

También existen diferencias en el modo en que se realiza el prorrateo de escaños entre circunscripciones. En un primer grupo de Comunidades Autónomas el reparto de diputados entre distritos electorales se hace combinando un doble criterio demográfico-territorial. La manera de proceder al reparto de escaños es similar a la empleada por el sistema electoral del Congreso de los Diputados: se asigna un mínimo inicial de escaños a cada circunscripción con independencia de la población que resida en ellas, y el resto de asientos hasta completar el Parlamento se reparte en función del número de habitantes de cada circunscripción. De este modo, el número de escaños asignados a cada circunscripción puede variar de unos comicios a otros. Por el contrario, otro grupo de Comunidades realiza un reparto rígido de escaños prefijado de antemano. Aunque no es un fenómeno exclusivo de este grupo de Comunidades, en aquellas donde se articula este reparto de diputados estático, como es el caso de Canarias, País Vasco o las Islas Baleares, se produce un importante prorrateo desviado de escaños o malapportionment, esto es, existe una distorsión en el reparto de escaños entre circunscripciones y la población que reside en ellas, que, en última instancia, produce problemas desde la perspectiva de la igualdad del voto ${ }^{8}$.

Asimismo, existe cierta disparidad en lo referente a barreras electorales. Algunas Comunidades Autónomas establecen el umbral legal en el 3 por ciento, siguiendo la estela del sistema electoral del Congreso de los Diputados. Otras, sin embargo, se han inclinado por el 5 por ciento. Por último, encontramos el caso extremo de Canarias,

${ }^{7}$ Los artículos 13-15 de la Ley 14/2015, de 28 de julio, de reforma de la Ley 2/1987, de 24 de febrero, Electoral de la Región de Murcia, han modificado el sistema electoral murciano, estableciendo, entre otras novedades, una circunscripción electoral única que engloba a todos los electores de la Región de Murcia. Se adopta así el criterio más común en las comunidades autónomas uniprovinciales (Cantabria, Navarra, La Rioja y Madrid), quedando el Principado de Asturias como la única comunidad exótica en este sentido.

${ }^{8}$ C, FERNÁNDEZ ESQUER y J. R. MONTERO, «El sistema electoral canario: representación desproporcional y desigualdad del voto», en G. PÉREZ y V. MÚJICA (coord.) Textos para la Reforma electoral de Canarias, Gran Canaria: Universidad de las Palmas de Gran Canaria, 2016, pp. 21-68. 
que establece un triple umbral electoral alternativo que los partidos deben superar para acceder al reparto de escaños: el 6 por ciento a nivel autonómico, el 30 por ciento a nivel insular, o ser la lista más votada en la respectiva circunscripción.

En definitiva, lo que se trata de poner de relieve es que, tras la aparente uniformidad de los componentes nucleares de los distintos sistemas electorales autonómicos, existen también ciertas diferencias, algunas de ellas muy significativas por cómo condicionan la conversión de votos en escaños y, en consecuencia, por cómo afectan al comportamiento de electores y partidos.

\section{El origen del sistema electoral gallego}

Tal y como sucedió en todas las comunidades autónomas, la Ley Orgánica 1/1981, de 6 de abril, de Estatuto de Autonomía para Galicia, también previó un sistema electoral provisional en tanto que no se aprobase la ley electoral definitiva9 ${ }^{9}$ La Disposición Transitoria Primera del Estatuto fijó el número de asientos de la Cámara en 71, repartiéndolos entre las cuatro circunscripciones de forma que estuviesen sobrerrepresentadas las provincias con una menor densidad demográfica como eran Lugo y Ourense, a costa de infrarrepresentar a las más pobladas, A Coruña y Pontevedra. El precepto determinaba que el número de escaños que le correspondían a cada circunscripción fuera el siguiente: A Coruña 22; Lugo 15; Ourense 15; y Pontevedra 19.

Así, mientras que A Coruña ostentaba el 31 por ciento de los escaños con el 39 por ciento de la población gallega, Lugo y Ourense se hicieron con el 21 por ciento de los escaños con poblaciones que suponían el 15 y 16 por ciento de la Comunidad Autónoma, respectivamente. Esa fue la distribución provincial de diputados tanto en las elecciones de 1981 como en las de 1985. La justificación histórica a este reparto se fundamentó en la necesidad de alcanzar una mayor cohesión y vertebración territorial entre las zonas urbanas y las de carácter rural. En esencia, este mecanismo constituía una suerte de discriminación positiva en favor de las provincias esencialmente rurales que, de lo contrario, podrían ver postergadas sus demandas particulares ${ }^{10}$.

Ahora bien, esta operación no fue en absoluto inocente. Al contrario, si se atiende a la distribución geográfica del votante gallego, este prorrateo de escaños resulta determinante. Se buscaba premiar «de manera clara a la Galicia campesina, del interior, más atrasada económica, social y culturalmente sobre la Galicia urbana y costera, más moderna en todos los aspectos mencionados» ${ }^{11}$. A este respecto, cabe señalar

9 J. CALVET, «QQué sistemas electorales prefieren los partidos? El caso de los parlamentos regionales en España (1977-1983)», Revista de Estudios Políticos, núm. 175, 2017, pp. 67-110.

${ }^{10}$ F. MARTÍNEZ ARRIBAS (coord.), Análise das eleccións autonómicas galegas do 21 de outubro de 2012. Reflexións sobre o sistema electoral, Santiago de Compostela, Andavira, 2013.

11 R. BLANCO, R. MAIZ y J.A. PORTERO, Las elecciones en Galicia. 1. El Parlamento Gallego, A Coruña: Ediciones NOS, 1982, p. 83. 
que los preceptos estatutarios relacionados con el sistema electoral fueron impuestos por la UCD sin ser acordados con el resto de formaciones políticas. Esto explica, sin ir más lejos, por qué Lugo y Ourense, donde la UCD contaba con un gran respaldo electoral, fueron sobrerrepresentadas, frente a las otras dos provincias donde el apoyo a la UCD era más débil ${ }^{12}$.

El sistema electoral fue uno de los caballos de batalla durante la tramitación del Estatuto de Galicia. Como con acierto señala Blanco Valdés, «la competitividad (...) derivó de un doble orden de motivos: por un lado, el número y el reparto interprovincial de escaños que habían de componer la primera Asamblea autonómica y, por otro, la introducción de una barrera legal de votación, el tres por ciento del censo, para acceder a la Cámara» ${ }^{13}$.

En este sentido, debe recordarse que el proyecto de Estatuto elaborado en un primer momento por la Asamblea de Parlamentarios de Galicia, establecía un sistema electoral algo distinto al que finamente terminó aprobándose ${ }^{14}$. Por ejemplo, se establecía una franja de parlamentarios notablemente más elevada (entre 100 y 125 escaños). Además, el proyecto de Estatuto de Autonomía incorporaba una cláusula que exigía a las fuerzas políticas superar el 3 por ciento del censo electoral de la provincia para optar al reparto de escaños, lo cual implicaba la contabilización de la abstención. Esta propuesta suponía exigir en la práctica más de un 6 por ciento de los votos válidos, por lo que perjudicaba gravemente a las pequeñas formaciones, entre las que se situaban buena parte de los partidos nacionalistas gallegos ${ }^{15}$. Máxime si se tiene en cuenta que Galicia fue una Comunidad Autónoma notablemente abstencionista en perspectiva comparada, especialmente en los primeros procesos electorales ${ }^{16}$. Baste con señalar que en los primeros comicios al Parlamento de Galicia de 1981, la participación fue del 46,3 por ciento de los electores - lo que a día de hoy continúa representando el porcentaje de abstención más alto en unas elecciones autonómicas en la historia de España ${ }^{17}$.

12 A. X. LÓPEZ, Sistema político español e galego. Santiago de Compostela: Andavira, 2010, p. 144.

13 R. BLANCO, «Disposición Transitoria Primera», en J.L. CARRO FERNÁNDEZ-VALMAYOR (dir.), Comentarios al Estatuto de Autonomía de la Comunidad Autónoma de Galicia, Madrid: Ministerio para las Administraciones Públicas, 1991, p. 904.

14 Boletín Oficial de las Cortes Generales, n. ${ }^{\circ}$ 10-I, serie H, 20 de julio de 1979.

15 R. MÁIZ, «Título Preliminar», en J.L. CARRO FERNÁNDEZ-VALMAYOR (Dir.), Comentarios al Estatuto de Autonomía de la Comunidad Autónoma de Galicia. Madrid: Ministerio para las Administraciones Públicas, 1991, p. 17.

${ }^{16}$ Para más información sobre la abstención electoral en Galicia véase J.R., MONTERO, «La abstención electoral en las elecciones legislativas de 1982: términos de referencia, pautas de distribución y factores políticos», Revista de Derecho Político, núm. 22, 1986, pp. 103-147; M. JUSTEL, «Panorámica de la abstención electoral en España», Revista de Estudios Políticos, núm. 68, 1990, pp. 343-396; J. VILAS NOGUEIRA, «Las elecciones autonómicas de Galicia (1981-1990)», Revista de Estudios Políticos, núm. 75, 1992, pp. 59-85.

17 No obstante, hay que señalar que las tasas de participación en Galicia fueron pareciéndose a las de otras Comunidades Autónomas, llegando incluso a superar en ocasiones a otras «comunidades históricas» como Cataluña y el País Vasco, tal y como apunta S. MÍGUEZ, «De la apatía a la 
En el informe elaborado por la Comisión Constitucional, el número de parlamentarios se redujo hasta la horquilla actualmente vigente en el Estatuto (entre 60 y 80 escaños), siendo finamente 71 los asientos del primer Parlamento gallego. Más problemas suscitó la cláusula del 3 por ciento de los votos del censo electoral en cada provincia. De hecho, este elemento "pasó a convertirse en uno de los obstáculos más graves para la aceptación generalizada del Estatuto por las diversas fuerzas políticas, toda vez que esa cláusula, más allá de su significado puramente técnico, tenía una clara transcendencia política puesto que podía dar como resultado la privación de presencia parlamentaria a una gran parte de los partidos políticos y coaliciones electorales que venían presentándose a los comicios de las primeras elecciones generales del 15 de julio de $1977 »^{18}$.

En este punto, hay que señalar que, aunque el proyecto de Estatuto enviado a las Cortes Generales para su tramitación contó con un elevado grado de consenso entre las fuerzas políticas gallegas, el gobierno de la UCD, que pretendía racionalizar el proceso autonómico tras la aprobación de los Estatutos vasco y catalán, trató de recortar el nivel de autogobierno de Galicia. Esto generó un importante malestar entre los partidos políticos y la ciudadanía, que desembocó en una intensa movilización social en forma de importantes manifestaciones en las principales ciudades gallegas en contra de lo que se calificó como el «Estatuto do aldraxe» (Estatuto del agravio). Esta delicada situación, que generó tensiones incluso en el seno de la propia UCD, acabaría forzando el llamado «Pacto do Hostal». Así, a instancias de las fuerzas políticas que aceptaban la Constitución y el Estatuto de Autonomía, el Presidente de la Asamblea del Parlamentarios de Galicia, Antonio Rosón, remitió un escrito al Congreso de los Diputados ${ }^{19}$, en el que, entre otras cuestiones, se instaba a la supresión de los puntos más polémicos, con el objetivo último de solucionar las dificultades que impedían culminar el proceso estatutario gallego ${ }^{20}$. Finalmente, y como consecuencia de esta intervención, la Comisión constitucional decidió modificar los extremos más problemáticos del texto, que, en lo que afecta al sistema electoral, supuso el establecimiento de una barrera electoral provincial del 3 por ciento de los votos válidos y no del conjunto del censo electoral.

\footnotetext{
participación: la evolución de la abstención en las elecciones autonómicas de Galicia (1981-1997)», Sociológica, núm. 3, 1998, pp. 39-68., y S. MÍGUEZ, «Valores políticos y participación en Galicia: factores de cambio y continuidad», en J. L. VEIRA VEIRA (coord.), La evolución de los valores sociales en Galicia, 2010, pp. 127-170. También hay autores que sostienen que el déficit de participación electoral en Galicia no se sostiene empíricamente, sino que se debe a deficiencias censales de los electores residentes en el extranjero, dado el elevado número de emigrantes gallegos frente a la media española. En este sentido, véase I. LAGO, «El evanescente abstencionista gallego», Revista de Estudios Políticos, núm. 128, 2005, pp. 317-344.

18 Véase R. BLANCO, «Disposición..., ob. cit., p .905.

19 Boletín Oficial de las Cortes Generales, n. ${ }^{\circ}$ 10-II-1, serie H, 28 de octubre de 1980.

${ }^{20}$ Véase R. MÁIZ, «Título..., ob.cit., pp.17 y ss.; R. BLANCO, «Disposición..., ob. cit., pp. 904 y ss.
} 
Para finalizar con el esbozo de los orígenes del sistema electoral gallego, hay que mencionar una segunda fase, menos conflictiva, que se corresponde con la aprobación de la Ley 8/1985, de 13 de agosto, de elecciones al Parlamento de Galicia. Es preciso subrayar el elevado grado de consenso que caracterizó la aprobación de esta ley, que fue aprobada por la unanimidad de grupos parlamentarios de la Cámara en la votación final ${ }^{21}$. Por lo demás, esta ley electoral vino a consolidar los principales elementos del sistema electoral que operaron de forma provisional, siendo su única novedad reseñable el aumento del tamaño del Parlamento de Galicia de 71 a 75 escaños (artículo 9). Esta decisión estuvo motivada fundamentalmente por el afán de suavizar la desviación en el prorrateo de escaños creado por la Disposición Transitoria Primera del Estatuto de autonomía, por la que se rigieron los dos primeros comicios autonómicos ${ }^{22}$. Con la entrada en vigor del nuevo sistema electoral, que quedó diferida a las elecciones autonómicas de 1989, se redujo ligeramente el desequilibrio representativo que aún hoy persiste entre las provincias atlánticas de A Coruña y Pontevedra y las provincias del interior de Lugo y Ourense. Además, tras figurar en el proyecto de ley una barrera electoral del 5 por ciento de los votos emitidos, fue posteriormente rebajada de nuevo hasta el 3 por ciento, por entenderse que, en caso contrario, solo dos o tres fuerzas alcanzarían representación parlamentaria ${ }^{23}$.

\section{El sistema electoral gallego en la actualidad}

Para identificar los elementos que componen cada uno de los sistemas electorales autonómicos, hay que atender a la combinación del Estatuto de Autonomía y la ley electoral de cada Comunidad. En el caso del sistema electoral gallego, dos son los pilares normativos sobre los que se sustenta en la actualidad. Por un lado, el artículo 11 del Estatuto de Autonomía de Galicia; y, por otro, los artículos 8, 9 y 10 de la Ley 8/1985, de 13 de agosto, de elecciones al Parlamento de Galicia, reformada por la Ley 15/1992, de 30 de diciembre, que incrementó la barrera electoral del 3 al 5 por ciento de los votos válidos por circunscripción.

El Estatuto de Autonomía dispone que el Parlamento está constituido por Diputados elegidos por sufragio universal, igual, libre, directo y secreto (artículo 11.1). Del mismo modo, el Parlamento será elegido por un plazo de cuatro años de acuerdo con un sistema de representación proporcional que asegure, además, la representación de las diversas zonas del territorio gallego (artículo 11.2). Se establece también, tal y como hace lo hace la Constitución para el Congreso y el Senado y la mayoría de Estatutos de Autonomía para sus respectivas Asambleas autonómicas, que la circunscripción ha de ser la Provin-

${ }^{21}$ Diario de Sesiones del Parlamento de Galicia, I Legislatura, núm. 126, 19 de julio de 1985, p. 8847.

${ }^{22}$ F. MARTÍNEZ ARRIBAS, «Reflexiones sobre la non nata reforma de la lei de eleccións ao Parlamento de Galicia», Revista Dereito, núm. 21 (2), 2012, p. 23.

${ }^{23}$ J.A PORTERO, «Artículo 11», en J.L. CARRO FERNÁNDEZ-VALMAYOR (Dir.), Comentarios al Estatuto de Autonomía de la Comunidad Autónoma de Galicia. Madrid: Ministerio para las Administraciones Públicas, 1991, p. 131. 
cia (artículo 11.4). A esto habría que sumarle la horquilla de parlamentarios, entre 60 y 80, que también vendría establecida por el Estatuto de Autonomía gallego, pero que necesita de concreción en una ley electoral (artículo 11.5). Queda, pues, aplazado el número fijo de escaños a una ley de desarrollo básico del Estatuto de Galicia, cuya aprobación, y por extensión modificación, requeriría la mayoría absoluta del Parlamento gallego, según el artículo 127.1 del Reglamento del Parlamento de Galicia.

Ya se ha señalado que la ley electoral gallega de 1985 fijó en 75 el número de escaños del Parlamento (artículo 9.1). Lo más curioso es que, con el objetivo de respetar el mandato constitucional de asegurar la representación de las diversas zonas del territorio, se estableció un mínimo inicial de 10 diputados para cada una de las cuatro provincias (artículo 9.2), restando, pues, tan solo 35 diputados para repartir en función de criterios poblacionales (artículo 9.3). Desde la aprobación de la ley electoral y hasta la actualidad, el número de Diputados de cada provincia ha ido variando conforme a las fluctuaciones demográficas (Tabla 1). Por último, se establece una barrera electoral del 5 por ciento de los votos válidos emitidos en la circunscripción (que era del 3 por ciento con anterioridad a la reforma electoral de 1992) y la fórmula proporcional D`Hondt para la asignación de escaños (artículo 10).

Tabla 1. Características del sistema electoral del Parlamento de Galicia, 1981-2016

\begin{tabular}{|c|c|c|c|c|c|}
\hline Período & Referencia legislativa & $\begin{array}{l}\text { Tamaño do } \\
\text { Parlamento }\end{array}$ & $\begin{array}{l}\text { Fórmula } \\
\text { electoral }\end{array}$ & $\begin{array}{l}\text { Circunscripciones } \\
\text { (n. } .^{\circ} \text { escaños) }\end{array}$ & Barrera electoral \\
\hline $\begin{array}{l}1981 \\
\text { a } 1985\end{array}$ & $\begin{array}{l}\text { Art. } 11 \text { y } \\
\text { Disp. Trans. 1. a del } \\
\text { Estatuto de Galicia. }\end{array}$ & 71 & D’Hondt & $\begin{array}{c}\text { A Coruña (22) } \\
\text { Lugo (15) } \\
\text { Ourense (15) } \\
\text { Pontevedra (19) }\end{array}$ & $\begin{array}{c}3 \% \text { de los } \\
\text { votos válidos } \\
\text { emitidos por } \\
\text { circunscripción }\end{array}$ \\
\hline 1989 & $\begin{array}{l}\text { Art. } 11 \text { del Estatuto } \\
\text { de Galicia y arts. } 8 \text {, } \\
9 \text { y } 10 \text { de la Ley } \\
\text { electoral gallega. }\end{array}$ & 75 & D'Hondt & $\begin{array}{c}\text { A Coruña (24) } \\
\text { Lugo (15) } \\
\text { Ourense (15) } \\
\text { Pontevedra (21) }\end{array}$ & $\begin{array}{c}3 \% \text { de los } \\
\text { votos válidos } \\
\text { emitidos por } \\
\text { circunscripción }\end{array}$ \\
\hline 1993 & $\begin{array}{l}\text { Art. } 11 \text { del Estatuto } \\
\text { de Galicia y arts. } 8, \\
9 \text { y } 10 \text { de la Ley } \\
\text { electoral gallega. }\end{array}$ & 75 & D'Hondt & $\begin{array}{c}\text { A Coruña (24) } \\
\text { Lugo (15) } \\
\text { Ourense (15) } \\
\text { Pontevedra (21) }\end{array}$ & $\begin{array}{c}5 \% \text { de los } \\
\text { votos válidos } \\
\text { emitidos por } \\
\text { circunscripción }\end{array}$ \\
\hline $\begin{array}{l}1997 \mathrm{a} \\
2012\end{array}$ & $\begin{array}{l}\text { Art. } 11 \text { del Estatuto } \\
\text { de Galicia y arts. } 8, \\
9 \text { y } 10 \text { de la Ley } \\
\text { electoral gallega. }\end{array}$ & 75 & D'Hondt & $\begin{array}{c}\text { A Coruña (24) } \\
\text { Lugo (15) } \\
\text { Ourense (14) } \\
\text { Pontevedra (22) }\end{array}$ & $\begin{array}{c}5 \% \text { de los } \\
\text { votos válidos } \\
\text { emitidos por } \\
\text { circunscripción }\end{array}$ \\
\hline 2016 & $\begin{array}{l}\text { Art. } 11 \text { del Estatuto } \\
\text { de Galicia y arts. } 8, \\
9 \text { y } 10 \text { de la Ley } \\
\text { electoral gallega. }\end{array}$ & 75 & D’Hondt & $\begin{array}{c}\text { A Coruña (25) } \\
\text { Lugo (14) } \\
\text { Ourense (14) } \\
\text { Pontevedra (22) }\end{array}$ & $\begin{array}{c}5 \% \text { de los } \\
\text { votos válidos } \\
\text { emitidos por } \\
\text { circunscripción }\end{array}$ \\
\hline
\end{tabular}

Fuente: elaboración propia 


\section{CONSECUENCIAS POLÍTICAS DEL SISTEMA ELECTORAL}

El sistema electoral es uno de los factores más importantes para entender el formato del sistema de partidos de un país ${ }^{24}$. El caso de Galicia no es una excepción y, en buena medida, las reglas electorales autonómicas han condicionado la competición política entre los partidos gallegos y sus estrategias de coordinación. Transcurridos treinta y siete años desde las elecciones fundacionales de 1981, podría decirse que el sistema de partidos gallego habría atravesado dos etapas. Una fase inicial que abarcó los dos primeros comicios autonómicos, en los que existió cierta competitividad electoral entre los dos grandes partidos (PP y UCD en 1981; PP y PSOE en 1985), que se repartían la mayoría de escaños. Y una segunda fase, que cabe calificar como de partido predominante según la tipología propuesta por Giovanni Sartori ${ }^{25}$, en la que el PP habría encadenado hasta siete mayorías absolutas consecutivas (1989, 1993, 1997, 2001, 2009, 2012, 2016), de no ser por el bipartito entre el PSOE y BNG surgido de las elecciones de 2005.

Asimismo, el carácter de nacionalidad histórica y los hechos diferenciales como la lengua y la cultura propias, explican que en Galicia hayan existido movimientos nacionalistas que pronto se agruparon en torno a formaciones políticas que acabaron teniendo representación. Así, junto a los partidos de ámbito nacional han existido partidos nacionalistas y regionalistas con presencia parlamentaria, como Esquerda Galega-Partido Socialista Galego (EG-PSG), Coalición Galega (CG) y el Bloque Nacionalista Galego (BNG) ${ }^{26}$. Si bien es cierto que tras las elecciones de 1993 se produjo una simplificación de la oferta partidista en el espectro político nacionalista que situó al BNG como fuerza política preeminente entre los partidos de ámbito no estatal ${ }^{27}$. Esta situación condujo a que el espacio de competición de los partidos gallegos se estructurase en torno a dos ejes políticos o cleavages bien nítidos: izquierda-derecha, tanto desde el punto de vista económico como cultural; y centro-periferia, según la preferencia por una mayor centralización o descentralización del Estado ${ }^{28}$. Por último, cabe destacar más recientemente la aparición en 2012 de Alternativa Galega de Esquerda (AGE), coalición política de carácter nacionalista,

${ }^{24}$ M. DUVERGER, Political Parties: Their Organization and Activity in the Modern State. Nueva York: Wiley, 1954.

25 G. SARTORI, Partidos y sistemas de partidos. Madrid: Alianza editorial, 2005.

26 Para más información sobre los movimientos y partidos nacionalistas gallegos véase J.L. BARREIRO, «Da UPG ao BNG: o proceso organizativo do nacionalismo galego», en J.M, RIVERA (coord.), Os partidos políticos en Galicia. Vigo: Xerais, 2003; J.G. BERAMENDI, y X. M. NÚÑEZ, $O$ nacionalismo galego. Vigo: A Nosa Terra, 1996; R. MÁIZ, «Nación de Breogán: oportunidades políticas y estrategias enmarcadoras en el movimiento nacionalista gallego (1886-1996)», Revista de Estudios Políticos, núm. 92, 1996, pp. 33-75.

27 I. LAGO, «La coordinación electoral del nacionalismo gallego», Revista Internacional de Sociología, Vol. 62, núm. 39, 2004, pp. 35-61.

28 S. ALONSO, Challenging the State: Devolution and the Challenge of Partisan Credibility. Oxford: Oxford University Press, 2012. 
que incluyó a una importante escisión del BNG liderada por Xosé Manuel Beiras. Esta coalición sería el preludio de En Marea, una nueva coalición que concurrió a las últimas elecciones de 2016, formada por Podemos, Anova y diferentes agrupaciones ciudadanas que ya se presentaron con éxito en las elecciones municipales de mayo de 2015 .

Tabla 2. Resultados de las elecciones autonómicas al Parlamento de Galicia, $1981-2016$

\begin{tabular}{lrrrrrrrrrr}
\hline & 1981 & 1985 & 1989 & 1993 & 1997 & 2001 & 2005 & 2009 & 2012 & 2016 \\
\hline PP & 30,5 & 40,9 & 44,1 & 52,1 & 55,2 & 51,6 & 45,2 & 46,7 & 45,8 & 47,56 \\
UCD & 27,8 & & & & & & & & & \\
PSOE & 19,6 & 28,7 & 32,8 & 23,7 & 19,5 & 21,8 & 33,2 & 31 & 20,6 & 17,87 \\
BNG & 6,3 & 4,2 & 8 & 18,4 & 24,8 & 22,6 & 18,7 & 16 & 10,1 & 8,33 \\
EG/PSG & 3,4 & 5,7 & 3,8 & & & & & & & \\
PCG & 2,9 & & & & & & & & & \\
CG & & 12,9 & 6,4 & & & & & & & \\
AGE/ En Marea & & & & & & & & & 13,9 & 19,07 \\
\hline
\end{tabular}

Fuente: elaboración propia en base a: http://eleccions2016.xunta.gal

La Tabla 2 ofrece la evolución, en porcentaje de votos, de los partidos que han alcanzado representación parlamentaria en las distintas elecciones autonómicas. Dicha tabla muestra cómo las elecciones de 1981 destacaron por ser aquellas en las que la suma de los dos partidos con mayor respaldo electoral, la UCD y AP, arrojó el porcentaje de votos conjunto más reducido de la serie (un 58 por ciento), dato que evidencia la elevada atomización partidista que se produjo en esos comicios fundacionales. En el resto de elecciones los partidos más votados fueron el PP y el PSOE, con tres excepciones: las de 1997 y 2001, en las que el BNG sobrepasó al PSOE como principal partido de la oposición; y los últimos comicios de 2016, en los que la formación En Marea obtuvo un mayor número de votos que el PSOE, pese a que finalmente ambas organizaciones políticas terminarían cosechando un igual número de escaños.

La literatura suele identificar dos factores esenciales para explicar la fragmentación en los sistemas de partidos: la permisividad de los sistemas electorales y la intensidad de la estructura de cleavages $^{29}$. En algunas comunidades autónomas como Galicia, parece que la importancia del cleavage nacionalista o centro-periferia, que se entrecruza con la tradicional divisoria sociopolítica izquierda-derecha, explicaría en gran medida los niveles de fragmentación partidista. No obstante, no debe desdeñar-

29 I. LAGO, «Cleavages y umbrales: las consecuencias políticas de los sistemas electorales autonómicos, 1998-2000», Revista Española de Ciencia Política, núm. 7, 2002, pp. 131-158. 
se la contribución del sistema electoral a la hora de explicar el mayor o menor fraccionamiento de la oferta partidista. No en vano, el sistema electoral es uno de los factores que determinan el número de opciones políticas que tienen capacidad para acceder al Parlamento. La Tabla 3 ofrece la evolución del número efectivo de partidos electorales (NEPE), un índice que tiene en cuenta el número y el peso en votos de los partidos, y el número efectivo de partidos parlamentarios (NEPP), que pondera el número de partidos en el Parlamento con su peso en escaños, desde las primeras elecciones hasta las recientes de 2016. Pues bien, al observar la tabla se comprueba la notable diferencia existente entre el NEPE y el NEPP, sobre todo en las elecciones de 1981, 1985, 1989 y 2012. Estas cifras ponen de relieve el poderoso efecto reductor del sistema electoral galego ${ }^{30}$, que estaría actuando como una suerte de filtro de partidos que aspiran a entrar en el Parlamento de Galicia.

Tabla 3. Fragmentación de partidos en las elecciones autonómicas gallegas, $1981-2016^{a}$

\begin{tabular}{lccccccccccc}
\hline & 1981 & 1985 & 1989 & 1993 & 1997 & 2001 & 2005 & 2009 & 2012 & 2016 & Media \\
\hline NEPE & 4,55 & 3,61 & 3,19 & 2,71 & 2,62 & 2,64 & 2,79 & 2,84 & 3,35 & 3,23 & 3,15 \\
NEPP & 3,32 & 2,85 & 2,49 & 2,36 & 2,43 & 2,49 & 2,60 & 2,54 & 2,64 & 2,67 & 2,64 \\
\hline
\end{tabular}

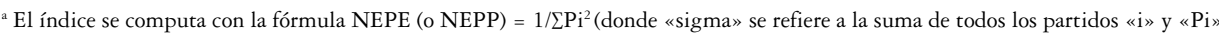
es la proporción de votos o de escaños del partido «i»)

Fuente: elaboración propia

Por otro lado, resulta imprescindible analizar la evolución de la desproporcionalidad electoral. Este concepto alude a la desviación agregada entre la proporción de votos obtenidos por los partidos, y la proporción de escaños que reciben ${ }^{31}$. Así, con un valor de 0 se cumpliría una proporcionalidad total, mientras que un valor de 100 indica una completa desproporcionalidad. Entre los factores que determinan la correspondencia entre votos y escaños, estarían el tamaño del Parlamento, el prorrateo desviado, la fórmula electoral, la barrera electoral y, sobre todo, la magnitud de distrito $^{32}$.

${ }^{30}$ G. SARTORI, Ingeniería constitucional comparada. México D. F.: Fondo de Cultura Económica, 1994.

31 A. LIJPHART, Sistemas electorales y sistemas de partidos. Un estudio de veintisiete democracias, 1945-1990. Madrid: Centro de Estudios Constitucionales, 1995.

32 Para una mayor información sobre los términos empleados para hablar del sistema electoral véase J. M. COLOMER, J. R. MONTERO e I. LAGO, «Glosario básico de sistemas electorales», Zona Abierta, núm. 110, 2005, pp. 349-358. Y, para completar la información sobre el efecto de la magnitud de distrito en la proporcionalidad en el caso español, véase J.R. MONTERO y P. RIERA, «El sistema electoral español: cuestiones de desproporcionalidad y reforma», Anuario de la Facultad de Derecho de la Universidad Autónoma de Madrid, núm. 13, 2009, pp. 225-270. 
La Tabla 4 muestra los niveles de desproporcionalidad alcanzados en las elecciones al Parlamento de Galicia en perspectiva histórica. La tendencia general apunta a una reducción progresiva de la desproporcionalidad, aunque cabe subrayar el repunte que se produjo en las elecciones de 2012 y en menor medida en 2016, lo que supone una aproximación a los valores del primer ciclo electoral. Este incremento vendría motivado por la aparición de nuevos actores políticos que compiten por un número limitado de escaños, quedándose algunos de ellos sin representación en la Asamblea gallega, como es el caso de Ciudadanos en 2016. La media de las diez elecciones arroja una desproporcionalidad de 4,8, lo que situaría al sistema electoral de Galicia como el décimo más desproporcional de España en promedio histórico, siendo superado por el sistema electoral del Congreso de los Diputados y otros ocho autonómicos ${ }^{33}$.

Tabla 4. Desproporcionalidad en las elecciones autonómicas gallegas, 1981-2016a

\begin{tabular}{llllllllllll}
\hline & 1981 & 1985 & 1989 & 1993 & 1997 & 2001 & 2005 & 2009 & 2012 & 2016 & Media \\
\hline MC & 8,39 & 6,54 & 6,4 & 4,33 & 2,63 & 2 & 2,86 & 3,09 & 6,45 & 5,35 & 4,8 \\
\hline
\end{tabular}

${ }^{a}$ La fórmula empleada para el cálculo de la desproporcionalidad es la de mínimos cuadrados de Gallagher, que emplea la siguiente fórmula: $\mathrm{MC}=\left[1 / 2 \sum\left(\mathrm{s}_{\mathrm{i}}-\mathrm{v}_{\mathrm{i}}\right)^{2}\right] 1 / 2$, donde $\left\langle\mathrm{v}_{\mathrm{i}}\right.$ » es el porcentaje de votos que consigue cada partido, $\mathrm{y}$ « $\mathrm{s}_{\mathrm{i}}$ » el porcentaje de escaños.

Fuente: elaboración propia

Estos que acaban de exponerse serían los denominados efectos mecánicos del sistema electoral, los cuales, al transformar los votos en escaños, generan una sobrerrepresentación de los primeros partidos, con la consiguiente infrarrepresentación de las terceras y cuartas opciones. En la Tabla 5 ofrecemos precisamente las primas y penalizaciones que reciben los partidos políticos debido a los efectos desplegados por el sistema electoral. El Partido Popular sería la fuerza más beneficiada por los sesgos mayoritarios del sistema electoral gallego, pues en todas las elecciones en las que ha participado resulta el partido con una mayor prima o bonificación. Esto es algo que ponen de relieve las cuatro mayorías fabricadas (manufactured majorities) ${ }^{34}$ alcanzadas en 1989, 2009, 2012 y 2016, coincidiendo las tres últimas con los gobiernos de Alberto Núñez Feijoo.

Aunque en menor medida que el PP, el PSOE también se ha servido de su posición de segunda fuerza política para obtener primas en términos de escaños, en relación a lo que le correspondería en un sistema perfectamente proporcional. Entre los

33 C. FERNÁNDEZ ESQUER y J.R. MONTERO, «El sistema...», ob. cit., pp. 21-68.

${ }^{34}$ Con este concepto se hace referencia a la situación en la que, debido a los efectos del sistema electoral, un partido se hace con la mayoría absoluta del parlamento sin haber alcanzado el 50 por ciento de los votos. Este fenómeno es característico de los sistemas mayoritarios, siendo poco frecuente en los sistemas proporcionales, tal y como señala D. RAE, The Political Consequences of Electoral Laws (2a ed). New Haven: Yale University Press, 1971. 
principales partidos, el gran perjudicado es el BNG. A excepción de los comicios de 2001 y 2009 donde obtuvo un porcentaje de escaños prácticamente equivalente al de votos recibidos, el BNG siempre ha resultado perjudicado por los efectos desproporcionales de las reglas electorales gallegas.

Tabla 5. Primas y penalizaciones electorales a los partidos, en las elecciones al Parlamento de Galicia, 1981-2016 ${ }^{\mathrm{a}}$

\begin{tabular}{lllllllllll}
\hline & 1981 & 1985 & 1989 & 1993 & 1997 & 2001 & 2005 & 2009 & 2012 & 2016 \\
\hline AP/PP & 6,12 & 7 & 6,7 & 5,2 & 3,8 & 3,06 & 4,13 & 3,96 & 8,86 & 7,1 \\
UCD & 6 & & & & & & & & & \\
PSOE & 2,93 & 2,28 & 4,6 & 1,6 & 0,5 & 0,87 & 0,13 & 2,3 & 3,4 & 0,8 \\
BNG & $-2,1$ & $-2,8$ & $-1,3$ & $-1,06$ & $-0,8$ & 0,06 & $-1,4$ & 0 & $-0,76$ & $-0,3$ \\
EG/PSG & -2 & $-1,5$ & $-1,13$ & & & & & & & \\
PCG & $-1,5$ & & & & & & & & & \\
CG & & 2,6 & $-0,93$ & & & & & & & \\
AGE/En & & & & & & & & & $-1,9$ & $-0,4$ \\
Marea & & & & & & & & \\
\hline
\end{tabular}

${ }^{a}$ La fórmula empleada para calcular las primas y penalizaciones es la siguiente: Primas y Penalizaciones $=\%$ escaños $-\%$ votos. Fuente: elaboración propia

Por último, es necesario abordar uno de los efectos más problemáticos del sistema electoral gallego: la desigualdad en el valor del voto. El mandato de representación territorial del artículo 152.1 CE y su heterogénea interpretación por parte de los legisladores autonómicos, derivó en el caso gallego en el establecimiento de un mínimo inicial de 10 escaños iniciales adjudicados a cada circunscripción electoral con independencia de su población. Como ya se ha adelantado, las provincias atlánticas (A Coruña y Pontevedra) se encuentran infrarrepresentadas frente a las provincias del interior (Lugo y Ourense) que son las menos habitadas. En términos prácticos, esto supone que la incidencia en el resultado final de un elector de Ourense o Lugo es aproximadamente el doble que la de un ciudadano de A Coruña o Pontevedra.

Esta desigualdad en el valor del voto queda reflejada en el prorrateo desviado de escaños o malapportionment. Este indicador captura la distorsión total existente entre la distribución real de escaños entre las distintas circunscripciones que componen un sistema electoral dado y la distribución de escaños que idealmente les correspondería si únicamente se siguiese a un criterio poblacional en el prorrateo de escaños. La existencia de malapportionment coincide con la presencia de desigualdad en el valor del voto de los ciudadanos, pues no todas las circunscripciones tendrían una igual ratio de electores y diputados.

Este fenómeno se produce de forma acusada en el caso del sistema electoral del Congreso de los Diputados. España, con un malapportionment del 14,6, ocuparía así el decimosexto puesto de la lista de países con mayor prorrateo desviado de escaños del 
mundo, el tercero de Europa y el primero entre los países de la Unión Europea ${ }^{35}$. Por lo que se refiere al caso de estudio, la Tabla 6 muestra los valores de malapportionment de las diez elecciones celebradas en Galicia. La mayor desviación del prorrateo tuvo lugar en los comicios celebrados en 2009 y 2012. Estos valores suponían que más de un 12 por ciento de los escaños se encontraban en una circunscripción donde no les correspondería de haberse seguido un prorrateo perfectamente proporcional. En perspectiva comparada, el caso gallego es el quinto con valores más elevados de las diecisiete Comunidades Autónomas españolas, y ocuparía el decimosexto puesto a nivel mundial, en una lista que lidera Tanzania ${ }^{36}$. En las recientes elecciones de 2016, aproximadamente un 11 por ciento de los escaños que se repartieron violaron el principio de igualdad del sufragio en un sentido material. Con todo, la distorsión representativa fue inferior a la registrada en elecciones anteriores, gracias al aumento de un escaño en la provincia de A Coruña.

Tabla 6. Prorrateo desviado de escaños en las elecciones al Parlamento de Galicia, $1981-2016^{\mathrm{a}}$

\begin{tabular}{lllllllllll}
\hline & 1981 & 1985 & 1989 & 1993 & 1997 & 2001 & 2005 & 2009 & 2012 & 2016 \\
\hline MAL & 10,82 & 11,45 & 9,78 & 11,97 & 11,5 & 11,55 & 11,9 & 12,24 & 12,23 & 10,96 \\
\hline
\end{tabular}

${ }^{a}$ La fórmula para calcular el malapportionment es la siguiente: $M A L=(1 / 2) \sum|s i-v i|$. Donde «si» es el porcentaje de escaños de una circunscripción y «vi» el censo electoral de la circunscripción.

Fuente: elaboración propia

\section{REFORMAS Y PROPUESTAS DE REFORMA DEL SISTEMA ELECTORAL GALLEGO}

\section{La polémica reforma de 1992}

En la que sería la primera de cuatro legislaturas consecutivas con Manuel Fraga Iribarne como Presidente de la Xunta, se aumentó del 3 al 5 por ciento la barrera legal del sistema electoral. Esta medida, adoptada en diciembre de 1992, fue aprobada únicamente con el voto a favor de los diputados del PP, sin contar con el apoyo del resto de fuerzas políticas presentes en el Parlamento de Galicia. Con ello se quebró el consenso alcanzado en la aprobación del Estatuto de Autonomía y de la propia ley

35 D. SAMUELS y R. SNYDER, «The Value of a Vote: Malapportionment in Comparative Perspective», British Journal of Political Science, núm. 31, 2001, pp. 651-671.

36 J.A. SEIJAS, «Análisis del grado de «Mal-apportionment» en los parlamentos autonómicos del Estado español», Revista Española de Ciencia Política, núm. 34, 2014, pp. 199-221. 
electoral gallega de 1985, que había situado la barrera electoral en el 3 por ciento $^{37}$. Además, esta reforma inauguró una tendencia orientada a endurecer las barreras de acceso al reparto de escaños que seguirían posteriormente las comunidades autónomas de Islas Baleares en 1995 y Canarias en 1996.

Por lo que se refiere a la motivación de la reforma, ésta perseguía favorecer la gobernabilidad y evitar la atomización ideológica. En opinión del propio Fraga, era necesario racionalizar y simplificar al máximo la geografía política del país y para ello nada mejor que endurecer las condiciones para acceder al Parlamento. Por su parte, la fundamentación que se puede leer en la propia exposición de motivos de la reforma alude a «una lógica adaptación de la ley al nivel de implantación social de las fuerzas políticas y a la búsqueda de la máxima eficacia en la actuación del Parlamento» ${ }^{38}$.

Sin embargo, estos argumentos en pos de la estabilidad y la racionalización parlamentaria resultan cuando menos llamativos, dado que por aquel entonces el PP gozaba de una mayoría absoluta en la Cámara. En aquellos momentos tenían representación parlamentaria otros cuatro partidos políticos (PSOE, BNG, CG y PSG-EG) y dos de ellos de una forma prácticamente testimonial, pues contaban cada cual con tan solo dos diputados.

Así las cosas, parece que el verdadero propósito de la reforma fue el de dejar fuera de juego a las pequeñas organizaciones nacionalistas, algunas de ellas con representación parlamentaria en ese momento. En opinión de Pallarés ${ }^{39}$, esta modificación pretendía «evitar la emergencia y desarrollo de grupos galleguistas en el centro-derecha que pudieran erosionar electoralmente al PP y hacerle perder la mayoría absoluta».

Esta interpretación sobre la intencionalidad partidista de la reforma fue la que hicieron todos los partidos de la oposición durante la tramitación parlamentaria. Así, el representante de Coalición Galega, Cándido Sánchez Castiñeiras, reprochaba a los populares las repercusiones negativas que la reforma podía tener, no tanto por los efectos mecánicos sino por los efectos psicológicos: «Lo que pretende, en el fondo, es tratar de eliminar a las fuerzas políticas que saben que tienen una ideología galleguista (...). Todas las fuerzas políticas representadas hoy superan el 7 por ciento de los votos; ahora bien, el engaño que pretende llevar a cabo el Partido Popular consiste en decir que si subimos al 5 por ciento, por ejemplo Coalición Galega no estará representada en la próxima legislatura. Sabemos que esto no es cierto, pero articulado con propaganda (...) puede tener un efecto disuasorio sobre aquellos que quieran votar a una determinada fuerza» ${ }^{40}$.

37 F. MARTÍNEZ ARRIBAS, «Reflexiones sobre la non nata reforma de la lei de eleccións ao Parlamento de Galicia», Revista Dereito, núm. 21 (2), 2012, p. 25.

38 Ley 15/1992, de 30 de diciembre, por la que se modifica la Ley 8/1985, de 13 de agosto, de Elecciones al Parlamento de Galicia. Publicado en el BOE núm. 46, de 23 de febrero de 1993.

39 F. PALLARÉS, «Los sistemas...», ob. cit. p. 239.

40 Diario de Sesiones del Parlamento de Galicia, III Legislatura, núm. 124, 8 de septiembre de 1992, p. 2183. 
El representante del BNG mantenía un posición similar: «Efectivamente, la gravedad está en la intoxicación; la gravedad está en que el señor Fraga Iribarne, pretende en todo caso o, en el mejor de los casos, adquirir un diputado en la provincia de A Coruña que le podría garantizar una mayoría absoluta que en este momento no le garantizan los sondeos. Precisamente, debido a que no le garantizan esa mayoría absoluta, por eso eleva el listón al 5 por ciento» ${ }^{41}$.

En parecidos términos se expresaba el representante del PSOE, Sánchez Presedo: «A mí me gustaría saber: ¿Qué tiene este Gobierno contra el nacionalismo más moderado? Porque realmente esta ley lo que pretende hacer no es una prevención (...) sino que es una tela de araña de la democracia, una tela de araña para el nacionalismo moderado de este país» ${ }^{42}$.

En realidad, todas estas acusaciones eran reconocidas de forma implícita por el propio representante del Partido Popular, Vázquez Portomeñe: «(...) de esta manera tratamos de disuadir futuras presencias electorales y, en definitiva, más que disuadirlas hacer que se aglutinen de forma coherente, que representen el mayor estrato posible de la sociedad. (...) No se trata de bloquear, se trata de animar a quien se vea en ese peligro (...) a que se arrime a quien se debe arrimar, busque la coherencia ideológica y no atomice la manifestación de la voluntad de los gallegos a través de las urnas, esa es la historia» ${ }^{43}$.

Este aumento del 3 al 5 por ciento situó la barrera legal en niveles superiores al umbral efectivo de voto ${ }^{44}$ en las circunscripciones de A Coruña y Pontevedra, provincias donde los partidos minoritarios tenían más opciones de obtener representación. De hecho, en las elecciones inmediatamente posteriores, las de 1993, la coalición Esquerda Unida-Unidade Galega obtuvo un 3,74 por ciento de los votos en la circunscripción de A Coruña, porcentaje que, de no haberse incrementado la barrera electoral al 5 por ciento, le habría permitido hacerse con un escaño.

No es de extrañar que el aumento de la barrera legal fuera uno de los factores que contribuyera a erradicar definitivamente la proliferación de pequeños partidos en Galicia. Frente a la dispersión originaria, sobre todo del voto nacionalista, emergió una paulatina concentración de fuerzas buscada por la clase política. Las diversas familias nacionalistas, con su diversidad de matices, dieron origen a un proceso tortuoso de confluencia ${ }^{45}$.

${ }^{41}$ Diario de Sesiones del Parlamento de Galicia, III Legislatura, núm. 138, 24 de noviembre de 1992, p. 3489.

42 Diario de Sesiones del Parlamento de Galicia, III Legislatura, núm. 124, 8 de septiembre de 1992, p.2203.

43 Diario de Sesiones del Parlamento de Galicia, III Legislatura, núm. 124, 8 de septiembre de 1992, p. 2196.

${ }^{4}$ El umbral efectivo es el porcentaje de votos que debe acumular un partido para conseguir representación en una circunscripción; se calcula de acuerdo a la fórmula propuesta por A. LIJPHART, Sistemas electorales..., ob. cit. pp. 63 y ss.

45 I. DIZ, N. LAGARES, J. RIVERA y A. CASTRO, «Sistema electoral y elecciones autonómicas en Galicia», en J. MONTABES (ed.), El sistema electoral a debate. Veinte años de rendimientos del sistema electoral español. Madrid: Centro de Investigaciones Sociológicas/Parlamento de Andalucía, 1998. 
En definitiva, en solitario, a unos pocos meses de las elecciones, y con el argumento oficial de evitar la fragmentación parlamentaria, favorecer la gobernabilidad y fomentar la coordinación partidista en torno a unas pocas siglas políticas, el PP de Galicia impulsó la primera reforma de un sistema electoral regional en la historia del Estado autonómico, con el propósito velado de eliminar contrincantes políticos de corte nacionalista y, más en general, de disuadir a potenciales rivales de intentar competir en la arena política gallega.

\section{Las propuestas de reforma electoral de 2012 y 2014}

Desde que estallase la grave crisis económica en 2008, hemos asistido a una avalancha de propuestas de reforma de los sistemas electorales autonómicos. Como forma de mitigar el descontento generalizado con los rendimientos del sistema político, los partidos parecen haber encontrado en la modificación de los sistemas electorales una respuesta a los problemas relacionados con el descrédito de las instituciones representativas. Ahora bien, conviene distinguir dos fases bien diferenciadas en cuanto a las propuestas de reforma electoral.

Comencemos por la segunda de las fases, que es la actual, y que arranca tras el cambio en el sistema de partidos que tiene lugar tras las elecciones autonómicas de 2015, caracterizado por la irrupción de Podemos y Ciudadanos en la mayor parte de Asambleas legislativas ${ }^{46}$. En la actual legislatura autonómica, es posible afirmar que, enarbolando la bandera de la regeneración democrática, los nuevos partidos están poniendo estratégicamente en la agenda política reformas institucionales a cambio de prestar su apoyo a los partidos tradicionales. Muchas de esas reformas se centran en el sistema electoral, y las principales propuestas aspiran conseguir una mayor proporcionalidad entre votos y escaños, una menor desigualdad en el valor del voto y una mayor proximidad entre representantes y representados. Sería el caso, por ejemplo, de la reciente modificación del sistema electoral murciano, que ha sustituido las antiguas cinco circunscripciones por un distrito electoral único que abarca el conjunto del territorio de la comunidad y ha reducido la barrera legal del 5 al 3 por ciento ${ }^{47}$ - Pero también el de otras comunidades con procesos ya en tramitación o en fases anteriores de estudio, tal y como sucede en el momento de escribir estas líneas en Asturias, Andalucía, Canarias o la Comunidad Valenciana.

No obstante lo anterior, conviene retrotraerse a la primera fase de reformas electorales a nivel autonómico desde el estallido de la crisis. Esta primera etapa se inicia en 2011, año en el que el PP se hizo con una holgada mayoría absoluta en el Congre-

46 T. RODÓN y M. J. HIERRO, «Podemos and Ciudadanos shake up the Spanish party system: the 2015 local and regional elections», South European Society and Politics, núm. 21(3), 2016, pp. 339357.

${ }^{47}$ J. SIERRA, El sistema electoral de la Región de Murcia: regulación, balance (1983-2015) y perspectivas. Madrid: Dykinson, 2017. 
so de los Diputados, que se sumó a un poder autonómico y municipal sin precedentes. Por lo que respecta al nivel regional, el PP llegó a gobernar en once de las diecisiete comunidades autónomas, y en nueve de ellas lo hizo con mayoría absoluta. Ese enorme poder institucional permitió a este partido plantear un buen número de propuestas de reforma electoral. Mientras que en algunas regiones se limitó a anunciarlas o intentó ejecutarlas sin reunir los apoyos necesarios, en otras consiguió aprobarlas. Su denominador común consistió en la reducción del tamaño de las Asambleas autonómicas por razones de austeridad y de contención del gasto público. Este fue el caso, por ejemplo, de la reforma electoral de Cantabria del año 2012, por la que se redujo el tamaño del Parlamento en cuatro diputados, pasando de 39 a 35.

Sin embargo, fue la reforma del sistema electoral de Castilla-La Mancha la que alcanzó una mayor relevancia mediática. Y es que, sorprendentemente, el sistema electoral castellano-manchego fue objeto de dos reformas electorales en un corto espacio de tiempo, acometidas ambas por el PP en solitario. En la primera, en el año 2012, se amplió el tamaño del Parlamento de 49 a 53 escaños, con el objetivo de ajustar el reparto de escaños entre las provincias a su evolución demográfica. Lo llamativo es que la segunda, que tuvo lugar solo dos años después, en 2014, redujo el tamaño de las Cortes de Castilla-La Mancha de 53 a 33 escaños, convirtiendo en papel mojado — pues no llegó a aplicarse a ningún proceso electoral—, su anterior reforma de 2012. Esta modificación redujo de manera drástica el número de escaños de la cámara regional, convirtiéndola en la que menos diputados tiene de toda la España autonómica. La baja magnitud de las circunscripciones, además de producir unos resultados muy desproporcionales, generó unos altos umbrales efectivos que dificultaron sobremanera la presencia de terceros partidos en el Parlamento de Castilla-La Mancha. De hecho, en las elecciones autonómicas de 2015 Ciudadanos, con un 8,6 por ciento de los votos, se quedaría finalmente sin representación ${ }^{48}$.

Pues bien, si estudiamos el caso gallego en esa primera etapa de reformas electorales auspiciadas por el PP, encontramos una propuesta de modificación electoral del gobierno de Alberto Núñez Feijoo, en la que se buscaba reducir el tamaño del Parlamento $^{49}$. La disminución del número de escaños del Parlamento de Galicia fue anunciada por el presidente de la Xunta en una entrevista en el periódico La Voz de Galicia y fue presentada formalmente por el Grupo Parlamentario Popular en forma de

${ }^{48}$ C. FERNÁNDEZ ESQUER, «La reforma del sistema electoral de Castilla-La Mancha de 2014», Cuadernos Manuel Giménez Abad, núm. 11, 2016, pp. 76-85.

${ }^{49}$ Lo cierto es que desde la reforma de 1992 no se registraron intentos relevantes de modificar el sistema electoral gallego. Ni siquiera durante la VII legislatura, en la que tuvo lugar la alternancia en la Xunta con el gobierno bipartito de PSOE y BNG, se tramitó una propuesta que equilibrase el reparto de escaños entre las cuatro provincias gallegas para ajustarlo al peso demográfico de cada una de ellas. Y ello a pesar de que el Presidente de la Xunta, Emilio Pérez Touriño, llegó a anunciar una modificación de la ley electoral para hacer una mejor distribución de asientos en relación a la población. No obstante, la propuesta ni tan siquiera comenzó su andadura parlamentaria. 
proposición de ley en julio de 2012. Esta propuesta formaba parte de un paquete más amplio de medidas para el ahorro económico.

La proposición de ley pretendía reducir de 75 a 61 el número de parlamentarios previsto en el artículo 9.1 de la ley electoral gallega. Como en un principio el mínimo inicial de escaños para cada provincia se mantenía en 10, también se veía modificado el número de asientos que le correspondían a cada provincia en función de su población, pasando de 35 a 21. Sin embargo, la disolución anticipada del Parlamento gallego y la convocatoria de elecciones para que se celebrasen en octubre de 2012 coincidiendo con las elecciones vascas, impidieron que esa modificación electoral iniciase siquiera su tramitación parlamentaria ${ }^{50}$.

El espíritu de esta reforma fue rescatado en 2014, aunque con una leve modificación. Así, esta segunda propuesta, además de incluir una rebaja de los escaños del Parlamento a 61, como en la propuesta de 2012, contemplaba la reducción de 10 a 8 del mínimo inicial de diputados que se otorgan a cada circunscripción con independencia de su población.

Lo primero que debe subrayarse es que, debido a la reducción del número de escaños totales, ambas propuestas de reforma supondrían que las circunscripciones más pobladas resultasen aún más infrarrepresentadas de lo que lo están en la actualidad. De esta forma, lo que se habría conseguido sería un sistema electoral que saldría peor parado en lo relativo a la ratio de habitantes por escaño en cada circunscripción. Además, pasaría a tener un tamaño menor al de otras comunidades autónomas con menor población y menos provincias, como es el caso de Aragón y Extremadura.

Si se realiza una simulación en la que se apliquen a las pasadas elecciones de 2016 los sistemas electorales propuestos por el PP en 2012 y 2014, los populares ganarían de nuevo las elecciones, pero la novedad radicaría en que incrementarían ligeramente su porcentaje de escaños, tal y como se observa en la Tabla 7.

Tabla 7. Simulación electoral con las propuestas de reforma del PP para las elecciones autonómicas de 2016.

\begin{tabular}{lcccc}
\hline $\begin{array}{l}\text { N. }{ }^{\circ} \text { Escaños con } \\
\text { propuesta 2012 }\end{array}$ & \% Escaños & $\begin{array}{l}\text { N. }{ }^{\circ} \text { Escaños con } \\
\text { propuesta 2014 }\end{array}$ & \% Escaños \\
\hline PP & 35 & 57,4 & 34 & 55,7 \\
PSdG & 11 & 18 & 11 & 18 \\
En Marea & 11 & 18 & 12 & 19,7 \\
BNG & 4 & 6,6 & 4 & 6,6 \\
\hline
\end{tabular}

Fuente: elaboración propia

${ }^{50}$ F. MARTÍNEZ ARRIBAS, «Reflexiones sobre...», ob. cit. pp 1-33. 
El resto de partidos mantendría su posición, aunque verían reducidos su porcentaje de escaños, a excepción de En Marea, que con la propuesta defendida por el PP en 2014, vería como su porcentaje de escaños subiría en un escaso 1 por ciento. El BNG, por su parte, perdería con ambas propuestas el 1,4 por ciento de los escaños respecto a los alcanzados en 2016.

En suma, de haberse celebrado las elecciones de 2016 bajo las reglas electorales propuestas en 2012 y 2014, habrían aumentado las bonificaciones electorales para el PP, se habría reducido la fragmentación partidista por las mayores dificultades que habrían afrontado las pequeñas formaciones para entrar al Parlamento, y habría crecido la desigualdad del voto y la desproporcionalidad electoral. En definitiva, ambas propuestas estarían lejos de corregir las disfuncionalidades del sistema electoral gallego y, más bien, irían en la línea de la reforma de 1992, buscando hacerlo menos permeable.

\section{UNA HUMILDE PROPUESTA DE REFORMA ELECTORAL}

Una vez mostrados tanto la evolución como los rendimientos del sistema electoral gallego, estamos en disposición de plantear una propuesta de reforma, con el objetivo de solventar algunos de los problemas que se han ido desgranando. Y es que, a pesar de que Galicia ha sido una de las pocas Comunidades Autónomas que ha modificado ligeramente su sistema electoral y en la que además se han formulado propuestas para reformarlo recientemente, no nos parece que dichas propuestas fuesen acertadas a la hora de resolver sus disfunciones.

De entrada, hay que partir de que el artículo 11.4 del Estatuto de Autonomía preceptúa que la circunscripción electoral es la provincia; por lo que, en principio, se antoja difícil que, como forma de mejorar la proporcionalidad del sistema electoral gallego, sea viable otra circunscripción distinta a la provincial ${ }^{51}$.

Otra de las formas de corregir los problemas de proporcionalidad podría ser la modificación del tamaño del Parlamento. El número de escaños concreto que debe tener el Parlamento está fijado en el artículo 9.1 de la ley electoral. Así, para su modificación e incremento hasta los 80 escaños sería necesario la mayoría absoluta. Sin embargo, el incremento del número de diputados del Parlamento no parece necesario, puesto que actualmente tiene un tamaño que se ajusta razonablemente a las ratios de otras Comunidades Autónomas.

Por ello, y sin renunciar a un mínimo de escaños por cada provincia, consideramos que el mínimo inicial de escaños que debería otorgarse a cada provincia con independencia de su población es de 3 diputados, en lugar de los 10 actuales. De esta forma, el número de escaños a repartir siguiendo un criterio poblacional sería mucho mayor,

51 En los artículos 56 y 57 del Estatuto de Autonomía de Galicia, se especifica que para llevar a cabo esta reforma serían necesarios dos tercios del Parlamento de Galicia, la aprobación de la Reforma en las Cortes Generales mediante Ley Orgánica y la celebración de un referéndum. 
pues de los 35 actuales se pasaría a 63. El nuevo reparto de escaños dejaría a la provincia de A Coruña con 29 (4 más que actualmente), Pontevedra con 25 (3 más que actualmente), Lugo con 11 ( 3 menos que actualmente) y Ourense con 10 (4 menos que actualmente). Con estas magnitudes de distrito, todas las circunscripciones del sistema electoral gallego se encontrarían por encima del rango que va desde los 4 a los 8 escaños, y que algunos autores consideran como un punto óptimo electoral (electoral sweet-spot) para producir un virtuoso equilibrio entre una suficiente representatividad y una adecuada rendición de cuentas ${ }^{52}$.

Existen dos argumentos a favor de esta reducción del mínimo inicial de escaños por provincia. En primer lugar, consideramos que las propuestas que han defendido otros autores, consistentes en reducir ese mínimo de escaños a ocho ${ }^{53}$ o a $\operatorname{cinco}^{54}$, no servirían para mitigar lo suficiente la desigualdad en el valor del voto. Con nuestra propuesta, la máxima ratio de desigualdad del voto se amortiguaría notablemente, de tal forma que el valor del voto de un lucense sería tan solo 1,23 unidades superior al de un coruñés, y no del doble como sucede en la actualidad. En segundo lugar, la sobrerrepresentación de algunas circunscripciones puede propiciar una vertebración territorial equilibrada. De modo que, una ligera desviación en el prorrateo de escaños, entendida como un mecanismo compensatorio, constituiría un medio útil para que algunos territorios —especialmente aquellos más despoblados, de carácter rural, o con núcleos de población dispersos - puedan lograr en mayor medida la satisfacción de sus intereses a través de los representantes políticos. En este sentido, esta reducción del mínimo inicial a tres escaños seguiría la pauta de lo observado en otros sistemas electorales autonómicos, como es el caso de Castilla y León y Castilla la Mancha. Estas dos comunidades autónomas —especialmente la primera — presentan similitudes respecto a Galicia en lo que se refiere al fenómeno de la dispersión demográfica y, a pesar de ello, sus legisladores no han decidido establecer un mínimo de escaños por provincia mayor.

Por otra parte, a esta propuesta debería sumársele la necesidad de bajar la barrera legal el 5 al 3 por ciento a nivel provincial, retornando a la cuantía original ${ }^{55}$. Hasta la fecha, la estabilidad del sistema de partidos gallego ha sido formidable, como pone de manifiesto el dato de que en siete de las diez elecciones autonómicas celebradas el PP haya conseguido la mayoría absoluta de escaños. Así pues, no parece que el hecho de reducir la barrera en dos puntos, incrementase las posibilidades de entrada de nuevos partidos, y mucho menos que ello supusiese una amenaza para la estabilidad

52 J.M. CAREY y S. HIX, «The Electoral Sweet-Spot: Low-Magnitude Proportional Electoral Systems», American Journal of Political Science, núm. 55 (2), 2011, pp. 383-397.

53 F. MARTÍNEZ ARRIBAS, «Reflexiones sobre...», ob. cit. pp. 1-33.

54 A.X., LÓPEZ, «Hipóteses verbo dalgúns elementos do futuro sistema electoral galego», en A.X. LÓPEZ (coord.), O Terceiro Estatuto Galego. Propostas desde a Ciencia Política, Santiago de Compostela: Tórculo Edicións, 2006, p. 251; véase también J.A. SEIJAS, «Índice de Poder Provincial en el Parlamento de Galicia», Anales de Economía, núm. 20, 2012, p.14.

55 A.X., LÓPEZ, «Hipóteses verbo dalgúns elementos do futuro sistema electoral galego», ob cit. , p. 252. 
del sistema parlamentario gallego. Esta operación no sería meramente cosmética. Así, dado que los umbrales efectivos de Pontevedra (2,92 por ciento) y A Coruña (2,53 por ciento) se sitúan precisamente por debajo de ese 3 por ciento, la barrera electoral podría tener alguna virtualidad, siempre y cuando los partidos obtuviesen un porcentaje de votos que se situase entre los umbrales efectivos y la barrera en cuestión.

Por último, consideramos necesario cambiar la fórmula de reparto de escaños. Frente al método D’Hondt, que ha causado fortuna entre los legisladores electorales en España, consideramos pertinente la introducción de la cuota de reparto Hare, método que garantiza una mayor proporcionalidad al transformar los votos en escaños y, sobre todo, que elimina el sesgo en la adjudicación de escaños entre partidos más y menos votados.

A continuación, se realizará un ejercicio de simulación electoral con el objetivo de describir qué hubiese pasado si las últimas elecciones autonómicas se hubiesen celebrado con las reglas electorales propuestas, asumiendo que tanto partidos como electores se hubiesen comportado del mismo modo que lo hicieron bajo las reglas realmente existentes en 2016. La simulación se resume en la Tabla 8. En primer lugar, destacaría la entrada en el Parlamento de Galicia de dos nuevas fuerzas políticas, Ciudadanos y Democracia Ourensana (DO), con dos y un escaño, respectivamente. En segundo lugar, tanto En Marea como el BNG ganarían un diputado, gracias a la subida en escaños de las provincias atlánticas, donde su apoyo electoral es mayor. En tercer lugar, destaca la enorme pérdida de escaños del PP en las provincias rurales, Lugo y Ourense, donde se dejaría seis escaños. Por último, los resultados muestran que con nuestra propuesta electoral el PP no habría alcanzado la mayoría absoluta de escaños, por lo que tendría que haber llegado a acuerdos con otras formaciones políticas para mantenerse al frente del gobierno de la Xunta. Lo que pone de relieve esta simulación, en suma, es que la sobrerrepresentación del PP en el Parlamento de Galicia tiene mucho que ver con la actual sobrerrepresentación de las dos provincias del interior, Lugo y Ourense.

Tabla 8. Simulación electoral con la propuesta de reforma utilizando los resultados electorales de las elecciones al Parlamento de Galicia de 2016 ${ }^{\mathrm{a}}$

\begin{tabular}{lcccccc}
\hline & A Coruña & Lugo & Ourense & Pontevedra & Total & Total actual \\
\hline PP & $14(+1)$ & $6(-2)$ & $5(-4)$ & 11 & 36 & 41 \\
En Marea & $6(+1)$ & 2 & $1(-1)$ & $6(+1)$ & 15 & 14 \\
PSOE & 5 & $2(-1)$ & 2 & $5(+1)$ & 14 & 14 \\
BNG & $3(+1)$ & 1 & 1 & 2 & 7 & 6 \\
Ciudadanos & $1(+1)$ & & & $1(+1)$ & 2 & 0 \\
DO & & & $1(+1)$ & & 1 & \\
\hline
\end{tabular}

${ }^{a}$ La tabla incluye entre paréntesis los escaños que cada formación sube o baja en las distintas circunscripciones, tomando como referencia los resultados de los comicios de 2016.

Fuente: elaboración propia 
Las implicaciones de esta reforma para los rendimientos del sistema electoral serían muy significativas. De entrada, la fragmentación aumentaría, pasando de un sistema de 2 partidos y medio, que es el actual, a uno de tres partidos (el NEPP bajo estas nuevas reglas del juego sería de 3,18). La entrada de dos nuevas formaciones estaría detrás de este aumento. Del mismo modo, y como consecuencia más destacable de esta propuesta de reforma, la desproporcionalidad se corregiría casi totalmente, pasando a un índice de mínimos cuadrados del 1,38 por ciento, cuatro puntos por debajo del valor actual. A todo ello habría que sumarle la corrección en las primas y penalizaciones electorales para los partidos y, especialmente, en la igualdad del voto. Si con la ley actual, casi un 11 por ciento de los escaños estarían asignados a circunscripciones donde no les correspondería de seguirse un prorrateo estrictamente poblacional, este porcentaje se reduciría a un 1,8 por ciento, el más bajo en relación con el resto de comunidades autónomas.

\section{CONCLUSIONES}

La celebración de diez elecciones al Parlamento de Galicia nos ha permitido evaluar los rendimientos del sistema electoral gallego en términos de proporcionalidad, igualdad del voto y representatividad. Además, hemos estudiado la génesis del sistema electoral gallego en los albores del proceso autonómico, así como las distintas reformas y propuestas de reforma que a lo largo de este tiempo se han formulado en la comunidad gallega. Ello nos ha permitido estar en mejores condiciones para plantear una propuesta de reforma electoral en una dirección opuesta a las que se han ido sugiriendo en los últimos tiempos.

A la luz de lo expuesto en este trabajo, el caso gallego reitera una de las conclusiones más robustas en las investigaciones dedicadas a los sistemas electorales: se trata de una de las instituciones más susceptibles de ser manipuladas políticamente. La simulación electoral bajo unas nuevas reglas electorales que respetasen los principios de proporcionalidad y representación territorial establecidos en la Constitución Española sin necesidad de modificar el Estatuto de Autonomía de Galicia son muy elocuentes: en las recientes elecciones autonómicas de 2016 entrarían nuevos partidos en el Parlamento gallego y el PP perdería la mayoría absoluta, por lo que tendría que explorar apoyos para mantenerse el gobierno.

En definitiva, tras haber realizado un análisis descriptivo de la historia del sistema electoral gallego, así como de sus repercusiones políticas, creemos haber argumentado suficientemente la necesidad de una reforma puntual de algunos de sus elementos. El objetivo último sería conseguir que el Parlamento de Galicia reflejase de una manera más fiel las distintas sensibilidades sociopolíticas expresadas por el electorado de las cuatro provincias, sin que por ello se viera resentida la gobernabilidad de la que históricamente puede presumir el sistema político gallego. 
Title:

The Galician electoral system: to reform, or not to reform, that is the question.

\section{Summary:}

I. Introduction. II. The Galician electoral system. 1. The regional electoral context. 2. The origin of the Galician electoral system. 3. The Galician electoral system at present. III. Political consequences of the electoral system. IV. Reforms and reform proposals of the Gacilician electoral system: 1. The controversial reform of 1992. 2. Proposal reforms of 2012 and 2014. V. A humble electoral reform proposal. Vi. Conclusions.

\section{Resumen:}

Desde que Galicia alcanzase la autonomía política hasta los últimos comicios regionales de septiembre de 2016, se han celebrado un total de diez elecciones para elegir a los representantes del Parlamento de Galicia. Transcurrido este tiempo, es posible analizar los rendimientos del sistema electoral gallego (en términos de proporcionalidad, fragmentación partidista, desigualdad en el valor del voto y primas y penalizaciones a los partidos), así como indagar en los debates sobre su origen y modificaciones posteriores. Tras la aprobación del Estatuto de Autonomía en 1981, el sistema electoral gallego fue reformado en 1992 para aumentar la barrera electoral y, más recientemente, se han planteado otras dos propuestas de reforma en los años 2012 y 2014 . Con todo, las reglas electorales se han mantenido estables desde aquella pequeña modificación de los años noventa, por lo que han continuado beneficiando a los partidos establecidos, al establecer barreras de entrada a otras formaciones políticas y generar desigualdades en el valor del voto. Por ello, en este artículo formulamos una propuesta de reforma electoral que, con pequeños retoques, podría corregir algunas de las deficiencias del sistema electoral gallego, sin por ello poner en riesgo la gobernabilidad y estabilidad política que han caracterizado al subsistema político gallego durante estos años de autonomía política.

\footnotetext{
Abstract:

Since Galicia reached its political autonomy until the last elections of September of 2016, ten regional elections of the representatives for the Galician Parliament have been held. In the course of this time, it is possible to analyze the Galician electoral system's yields (in terms of proportionality, party fragmentation, malapportionment, and premiums, as well as penalties to the parties), and inquire in the debates about its origin and later modifications. After the approval of the Autonomous Statute in 1981, the Galician electoral system was changed in 1992 to increase the electoral threshold and, more recently, two proposals of reform have been
} 
suggested in 2012 and 2014. Yet, the electoral rules have remained stable since the slight modification in the nineties, so they have continued to benefit the established parties, by creating barriers preventing the entrance of other parties and generating inequality in the value of the vote. Thus, in this paper we propose an electoral reform that, with minor changes, could solve some problems of the Galician electoral system, without jeopardizing the governability and political stability that have characterized the Galician political subsystem during these years of political autonomy.

\section{Palabras clave:}

Sistema electoral gallego, elecciones autonómicas, reforma electoral

Key words:

Galician electoral system, autonomous elections, electoral reform. 